\title{
EDICIONES VICTIMADAS
}

Bulmaro Reyes*

RESUMEN: Mediante cinco ejemplos, dos antiguos y tres modernos, el autor consigue mostrar cómo el trabajo de edición cobra víctimas, aun sin quererlo, y además describe obras importantes para cualquier lector interesado en la historia mexicana y su dignidad.

PALABRAS CLAVE: editar, Rhetorica ad Herennium, Marcial, García Naranjo, Eguiara y Eguren, Abad.
ABSTRACT: Using five examples, of which two are old/ancient and three are modern, the author intends to demonstrate how editorial work takes victims, even unwillingly. He also describes significant works for readers interested in Mexican history and its dignity.

KEYWORDS: editing, Rhetorica ad Herennium, Marcial, García Naranjo, Eguiara and Eguren, Abad.

RECEPCIÓN: 20 de agosto de 2009.

ACEPTACIÓN: 23 de noviembre de 2009.

* Instituto de Investigaciones Filológicas, UNAM. 


\section{EDICIONES VICTIMADAS}

\section{E}

ditar en nuestra lengua significa:

1) Publicar por medio de la imprenta o por otros procedimientos una obra, periódico, folleto, mapa, etcétera. 2) Pagar y administrar una publicación. 3) Adaptar un texto a las normas de estilo de una publicación.

4) Organizar las grabaciones originales para la emisión de un programa de radio o televisión. 5) Hacer visible en pantalla un archivo. Así, adquiere las responsabilidades de editor, cualquiera que publica, paga, administra, adapta u organiza lo que cada uno de estos incisos dice.

Para editar medianamente basta, por lo que a mí respecta, un poco de entusiasmo, un poco de estudio, un poco de buena suerte y un poco de dinero. Para hacerlo bien, la dosis de estudio debe ser mayor.

Enseguida mostraré cómo desde la antigüedad hasta la actualidad han existido libros que han sido víctimas del trabajo editorial, unos de un modo, otros de otro; en mayor medida unos, en menor medida otros, aun cuando el daño que sufrieron no haya privado de su valor sustantivo a ninguno.

Las obras de las que me ocuparé han sido, o son, si no necesarias, sí muy significativas en la educación y cultura de los pueblos; tomé dos de la antigüedad: la Rethorica ad Herennium de autor incierto y los Epigramas de Marcial, y tres de la actualidad: El crepúsculo porfirista de García Naranjo, la Bibliotheca Mexicana de 
Eguiara y Eguren, y la Disertación joco-seria de Abad.

\section{Caso 1:}

\section{Rhetorica ad Herennium, siglo IV}

Editor: bibliotecario desconocido. Imprenta: amanuense desconocido. Víctima: autor anónimo.

Este libro había sido escrito en los años ochenta antes de Cristo y había permanecido oculto por más de cuatro siglos en la antigua Tagasta (actual Souk Ahras, en África), donde alguien que era o bibliotecario o vendedor de libros, lo encontró hacia el año 350 de nuestra era. Al parecer estaba tan deteriorado que, entre sus muchos defectos, no quedó rastro ni de título ni de autor.

El bibliotecario o librero descubridor de que hablo, se entusiasmó tanto con su buena suerte que, acaso, decidiera hacer negocio con su descubrimiento. Fundo esta suposición en que tal objeto era lo que hoy se conoce como "libro de texto", y ciertamente así funcionó por más de diez siglos, desde su hallazgo hasta el Renacimiento.

Ahora bien, aquel suertudo medio culto, en primer lugar había de poner autor y título a su libro, para lo cual le fue suficiente un poco de imaginación conducida por los mismos elementos del manuscrito. Lo llamo medio culto para salvarlo, ya desde este momento, de la grave censura de los modernos editores, que lo califican de ignorante, estulto, durmiente y bostezante.

En la primera página se hallaba un letrero que decía: romaniane uiuat romaniane uiuat; M. Tulli Ciceris. Esto significa: "viva Romaniano, viva Romaniano: Marco Tulio Cicer[ón]". Hay estudios que prueban que ese letrero no formaba parte del libro, sino que simplemente era la dedicatoria del solo ejemplar a un tal Romaniano que viviera en aquella época y en aquellos lugares. Pero, como haya sido, la fortuna puso ahí la inspiración para el nombre del autor: M. Tulli Ciceris $\approx$ Marco Tulio Cicerón. Además, la materia misma tenía numerosas coincidencias con otro libro que por aquel tiempo se hallaba en circulación y que hasta la fecha se llama De la invención retóri$c a$, escrito, precisamente, por aquel ruidoso orador romano.

De las numerosas coincidencias entre ambos libros, cuento una. En los dos, para explicar la ambigüedad de los escritos, se usa como ejemplo un testamento atribuido a un paterfamilias llamado Tulio, que a la letra reza: mi heredero dé a mi esposa Terencia 30 libras de los vasos argénteos que quiera, con la diferencia de que el verdadero Cicerón no dice ni Tulio ni Terencia. (La ambigüedad consiste en que el verbo "quiera" puede tener como sujeto a "mi heredero" o a "Terencia"). 
NOTAS

Se ha conjeturado que el nombre de Cicerón y el de Terencia no estaban en el original, ni fueron añadidos por el descubridor de que hablo, sino por editores posteriores, que se dieron cuenta de la mina de oro que explotarían si publicaban el libro bajo el nombre del famoso abogado romano.

Otra acusación que se hace al viejo editor es haber confundido liber con codex, razón por la cual dividió la obra en seis libros, en vez de conservarla en los cuatro de que en realidad consta.

Pero las razones más numerosas, no menos importantes, por las cuales se ha llamado durmiente y bostezante al antiguo editor son semejantes a nuestras erratas. Para muestra, escúchense estos ejemplos:

En vez de: decía:

\begin{tabular}{|c|c|}
\hline $\begin{array}{l}\text { castum }(I V, 23) \\
\text { casto }\end{array}$ & $\begin{array}{l}\text { cautum } \\
\text { cauto }\end{array}$ \\
\hline $\begin{array}{l}\text { integras }(I I I, 31) \\
\text { íntegras }\end{array}$ & $\begin{array}{l}\text { integravi } \\
\text { integré }\end{array}$ \\
\hline $\begin{array}{l}\text { sarisae Graeciae } \\
(I V, 43)\end{array}$ & varis egregie \\
\hline lanzas griegas & $\begin{array}{l}\text { caballetes } \\
\text { egregiamente }\end{array}$ \\
\hline $\begin{array}{l}\text { sequi suadebit } \\
(I I I, 8)\end{array}$ & si quis audivit \\
\hline aconsejará que siga & si alguien oyó \\
\hline $\begin{array}{l}\text { quibus liberi sunt } \\
\text { (IV, 37) } \\
\text { los que tenéis } \\
\text { hijos }\end{array}$ & $\begin{array}{l}\text { quibus liber } \\
\text { constat vitae } \\
\text { a quienes consta } \\
\text { el libro de la vida }\end{array}$ \\
\hline
\end{tabular}

Sin embargo, a pesar de los cientos de erratas y de los numerosos sinsentidos, el nombre de autor equivocado le dio a la obra el prestigio que, de otro modo, no hubiera gozado, iy por más de diez siglos! De hecho, cuando en 1490 resultó que Cicerón no era su autor, el libro cayó en desuso.

Y, no obstante todo ello, desde finales del siglo XIX, esta Retórica ha cobrado tanta fuerza que, aun en México, no ha pasado del todo inadvertida. En ella están reunidas las razones mediante las cuales la elocución oratoria puede ganar gravedad, dignidad y belleza. En ella se muestra el modo de hallar argumentos para cada género de discurso; la manera de disponerlos y de pronunciarlos. En ella se enseña el arte de la memoria. En ella, en breve, se aprende a descubrir con agudeza y prontitud; a disponer con distinción y orden; a pronunciar con gravedad y venustez; a memorizar con firmeza y para siempre. En ella, por ejemplo, San Jerónimo aprendió a hablar con adorno y suavidad.

\section{Caso 2:}

Spectacula, siglos IV-V

Editor: desconocido.

Imprenta: amanuense desconocido.

Víctima: Marcial (autor)

Marcial, el epigramatista latino, también sufrió a causa del cuidado 
de su editor. El daño infligido a su obra, de ser verdad, se debe no a ignorancia filológica del editor, sino a que aplicó la filología de otro modo, gracias al dominio que sobre ésta ejercía. Los manuscritos más importantes de donde se generó la tradición textual de Marcial se caracterizan por el hecho de que, en los pasajes escabrosos, el editor, me refiero al del siglo IV, reemplazó las palabras soeces por términos menos groseros, aun cuando haya conservado el sentido y la métrica de los originales, de modo especial en el libro de Los espectáculos.

Pero aun si esto fuera verdad, no habría lector que se privara de descubrir por sí mismo lo que de Marcial se dice, y acaso no le importara: que en los versos de Marcial, la sociedad romana se refleja con mayor intensidad que en cualquier otro escrito. El mismo autor declaró una vez que Roma entera podía reconocerse y contemplarse en sus versos, que podía encontrar en ellos el mismo sabor a hombre. Y hombre y vida son los nombres que mejor caracterizan su obra. En opinión de Gaston Boissier, nadie, en la literatura latina, es más vivo y más sincero que Marcial, pues no usa ideas generales, no hace descripciones vagas. Todos sus detalles son precisos. Guía al lector por los barrios donde algún parásito espera encontrar a alguien que lo invite a comer, por entre los comerciantes de cerillos o de salchichas, por entre mendigos y usureros de todo género. Marcial canta, pues, los pequeños hechos de la vida de todos los días, y supongo que la gran mayoría de sus lectores con frecuencia ni siquiera saben por qué tienen la oportunidad de leerlo, y mucho menos se interesan en considerar si la edición fue lícita o ilícita.

Hasta aquí, los editores de que hablo son desconocidos.

Con el tiempo, la conciencia del editor ha cambiado. Hoy el editor trasciende junto con la edición, a veces por exigencia, a veces muy a su pesar. Esto se ve en los colofones en los lugares donde los colofones se usan. Como en los siguientes ejemplos.

\section{Caso 3: \\ El crepúsculo porfirista. Memorias, año 1998}

Editor: Factoría Ediciones.

Imprenta: Factoría Ediciones, S. de R. L. Victimas: Nemesio García Naranjo (autor), Fernando Curiel (prologuista), Alberto María Carreño (epiloguista).

En el colofón de este caso se lee así: "esta obra se imprimió al cuidado de Factoría Ediciones SRL".

A pesar de este cuidado confesado, algún crítico socarrón llamaría 
NOTAS

durmiente y bostezante al editor, por haber, válgaseme el pleonasmo, editado el libro con acentos incorrectos en las formas verbales como escuchásteis, o por haber convertido a placer esdrújulas en llanas y llanas en esdrújulas, como carácteres o regimen, o volumenes, o por no haber acentuado los interrogativos indirectos, o por haberlos confundido, o por el montón de erratas, como apreciaciaciones, responió, frustado, espadadas, coantinuar, áquel, catigadora, Pateur, y otros centenares de dedazos.

Sin embargo, no debemos perder de vista que, gracias a Factoría Ediciones, es dable leer este libro del que no se puede prescindir en la historia de México. En muchos sentidos, ésta es obra fundamental: nadie que se precie de ser estudioso de la historia de México puede omitir su lectura; los adictos a la oratoria encontrarán en ella numerosos ejemplos teóricos y prácticos; los simples aficionados a la lectura, muchos motivos de placer, o, como el autor mismo dijera, "muchos pedazos de corcho en el Niágara gigantesco de la Revolución Mexicana".

\section{Caso 4:}

\section{Bibliotheca Mexicana, año 1986}

Editor: Universidad Nacional Autónoma de México / Coordinación de Humanidades.

Imprenta: Libros de México.

Víctimas: Juan José de Eguiara y Eguren (autor), Benjamín Fernández Valenzuela (prologuista y traductor) y Ernesto de la Torre Villar (autor del Estudio preliminar y coordinador de la serie).

El colofón de esta serie de libros dice: coordinó la edición Ernesto de la Torre Villar. La Biblioteca Nacional, junto con lo esencial de la ficha catalográfica, al describir el contenido de esta obra la divide en cuatro tomos, ${ }^{1}$ en tanto que las solapas de cada uno de los libros mismos prometen 5 volúmenes claramente clasificados. ${ }^{2}$

Pero, a la luz de los libros mismos, repito, nada de esto corresponde con

${ }^{1}$ Esta es la división: t. 1. Versión española, con un prólogo, estudio preliminar e inicio del catálogo, letra A. / t. 2. Versión española que contiene el final de la letra A y las letras B y C. / t. 3. Versión española del manuscrito inédito que contiene las letras $\mathrm{D}$ a la $\mathrm{J}$ del catálogo. / t. 4. Apéndices documentales e índices de toda la obra.

${ }^{2}$ Esta es la seriación publicada en cada solapa: vol . I. Versión latina facsimilar del volumen impreso en 1755. / vol . II. Versión española, con un prólogo, estudio preliminar e inicio del catálogo letra A. / Vol. III. Versión española que contiene el final de la letra A y las letras B y C. / vol. IV. Versión española del manuscrito inédito que contiene las letras D a la J del catálogo. / vol . V. Apéndices documentales e índices de toda la obra. 
la realidad. El tomus primus ${ }^{3}$ de la obra original -impresa en 1755 en la casa del mismo autor, Eguiara y Eguren- viene sin numeración de volumen en la edición de la Imprenta Libros de México. Así, puede considerarse el cero.

Desde luego, no considero ilícito ordenar de otro modo las ediciones modernas de libros viejos. Pero así como ésta quedó, me parece que más que orden tiene desorden.

Por ejemplo, el Sumario consta de dos partes: Prólogo de Benjamín Fernández Valenzuela, y Estudio preliminar por Ernesto de la Torre Villar. El Estudio preliminar, a su vez, está dividido en 15 incisos; pero los últimos tres de estos quince no pertenecen a ese estudio, sino que constituyen el objeto de la edición.

El sumario debió dividirse en tres incisos, el tercero de los cuales tendría que decir algo así como "Edición facsimilar", y abarcar lo que ésta contiene, es decir: el título, la dedicatoria a Fernando VI, la aprobación, la censura, el diálogo a propósito de la obra escrito por Vicente López, los veinte prólogos, el prefacio, la biblioteca misma desde la A hasta la $\mathrm{C}$, y finalmente la protestación del autor.

Pero ni siquiera las páginas son correctas: la 1 y la 2 con números

${ }^{3}$ Este tomus primus contiene: la dedicatoria a Fernando VI, la aprobación, la censura, el diálogo a propósito de la obra escrito por Vicente López, veinte prólogos, un prefacio, la biblioteca misma desde la A hasta la $\mathrm{C}$, y finalmente una protestación. arábigos se hallan después de la II romana, y la 3 y la 4, detrás de la VI romana; y, como sea que se cuente, a la sección de números romanos le sobran por lo menos seis páginas, y a la de arábigos le faltan cuatro.

Lo que acaso ocurrió fue que los editores modernos no vieron con claridad el título, y así mezclaron ad libitum las romanas entre las arábigas. La página 3, con tipografía del siglo XVIII, dice: BIBLIOTHECAE MEXICANAE TOMUS PRIMUS EXHIBENS LITTERAS A B C, lo cual significa TOMO PRIMERO DE LA BIBLIOTECA MEXICANA QUE EXHIBE LAS LETRAS A, B, C, como si el lector ya conociera la estructura general de esta obra, más bien desconocida hasta entonces.

Y no quiero parecer irónico, pero lo que no falta es el directorio de las principales autoridades universitarias, desde el rector hasta el coordinador de Humanidades.

Por último, pero no menos importante: el volumen $\mathrm{V}$ no corresponde a lo que se anuncia en la susodicha solapa clasificatoria; en realidad se llama Biblioteca mexicana (en español): Monumenta eguiarense (en latín), con la compilación, prólogo y notas de Ernesto de la Torre Villar, y con la colaboración de Ramiro Navarro de Anda. Y, en la página 2, como todos los volúmenes, también éste ostenta a las principales autoridades de la Universidad Nacional Autónoma de México. 
NOTAS

Aquí llamo la atención de los lectores: el título dice Monumenta eguiarense. Está mal: monumenta es sustantivo neutro plural, y eguiarense, así latinizado, es adjetivo neutro singular. Si esto realmente fuera latín tendría que decir Monumentum equiariense, o bien, Monumenta equiariensia. Esto no sería de gran momento: todos cometemos errores y todos tenemos ignorancias diversas; pero ocurre que los europeos de aquel entonces tenían la opinión de que los mexicanos éramos unos ignorantes, $y$, en especial, de que no sabíamos latín, y esa opinión era precisamente lo que pretendían aminorar no sólo Eguiara y Eguren sino también otros eruditos mexicanos, como abajo se verá.

De hecho, esta Bibliotheca Mexica$n a$ es un escrito fundamental en la historia de México: es acaso la primera defensa de lo mexicano, la obra más importante escrita por un criollo novohispano en el siglo XVIII. Su propósito fue doble: primero, vindicar la tremenda y atroz injuria que el español Manuel Martí, deán de Alicante, había hecho a México; segundo, demostrar que la infamante nota no podía ser sino hija de la ignorancia. Martí había dicho que México era el sitio de mayor barbarie del mundo entero, país envuelto en las más espesas tinieblas de la ignorancia y asiento y residencia del pueblo más salvaje que nunca había existido o pudiera existir, un pueblo que, con sus artes mágicas, podía volver demen- tes a los europeos, incluso a los más ilustrados y cultos, y podía transformarlos en seres semejantes a los más ignorantes animales.

En otras palabras, Eguiara y Eguren quería salvaguardar la dignidad del mexicano contra la opinión de los españoles, probando que en México brillaba ya la misma sabiduría que en el Viejo Mundo. Contiene, así, la historia de los escritores de cualquier cosa, en cualquier lengua, que hubieran nacido en la América boreal, como el autor llamaba a México, o que radicaran en ella, así se haya editado su obra o no; y se ocupa de modo especial en quienes llevaron a cabo hechos distinguidos o escribieron algo que tuviera que ver con el fomento de la fe católica y la piedad.

El siguiente libro es más específico acerca del conocimiento e ignorancia de la lengua latina.

\section{Caso 5:}

Disertación joco-seria, año $2000^{4}$

Editor: Universidad Autónoma de Aguascalientes.

Imprenta: Procesos Gráficos de UAA.

Víctimas: Diego José Abad (autor) y Roberto Heredia Correa (introductor y traductor).

Este libro, vindicador de lo mexicano igual que la Bibliotheca Mexicana,

${ }^{4}$ Diego José Abad, Disertación joco-seria: si alguien nacido fuera de Italia puede escribir correc- 
tiene en el colofón esta leyenda: "la edición estuvo al cuidado de Enrique Luján Salazar, diseño y formación Guillermo Silva".

Un libro tan pequeño como éste, de apenas cuatro pliegos de 16 páginas, no debería tener problemas. Sin embargo, presenta una docena de errores, erratas y descuidos, pero dos de éstos son graves, dado que dos páginas no puden leerse completas porque a ambas les sobran sendos renglones superiores, y a las dos les faltan sendos renglones inferiores. Alguna vez llegué a pensar que este tipo de problemas iba a desaparecer con la presencia de la computadora en las ediciones. $\mathrm{Me}$ equivoqué.

De todos modos, el mérito de la edición es superior a esas minucias de editor. Con esta obra, en efecto, el autor, teólogo mexicano, Diego José Abad, destruye a un soberbio ignorante italiano. Escribiendo en latín, defiende la capacidad intelectual de los no italianos, y pone en evidencia la estulticia de un hombre por demás ignominioso.

Se trata de una abierta burla al pobre italiano que tuvo la ocurrencia de poner por escrito, en una carta, algo realmente torpe y acaso ofensivo aun hoy en día en muchas comunidades.

tamente el latín, en contra de lo que opina Roberti, intr., trad. y nts. Roberto Heredia Correa, 2000, Aguascalientes, México, Universidad Autónoma de Aguascalientes, XLV $+20+20$ pp.
El infeliz italiano, que en vida se llamara Roberti, había dicho que solamente los italianos sabían escribir correctamente en latín, dado que las composiciones de los no italianos olían a cierta peregrinidad, y los oídos finos las rechazaban; los hombres de más allá de los Alpes o de allende el mar, desde su perspectiva, es decir, en América, no eran capaces de reconocer sus errores, ya que ni siquiera sospechaban si caían en incongruencias de ritmo, en complicación de frases o en la insolencia de los tropos.

Me alegra que Roberti no pudiera conocer la edición de la Bibliotheca Mexicana coordinada por don Ernesto de la Torre Villar... Lo que habría dicho.

Abad, por su parte, prueba que Roberti no se daba cuenta de que, desde hacía más de 200 años, los italianos seguían al no italiano Manuel Álvarez como su profesor de latín; no sabía, o no apreciaba, que los niños italianos aprendían a hablar en latín en los Diálogos del no italiano Luis Vives; no conocía el De ratione docendi et discendi del no italiano Joseph de Jouvency, pero ni siquiera al tampoco italiano Erasmo de Roterdam; en fin, que Roberti, el denostador de los no italianos, fue un mentecato que no supo siquiera hilvanar unos pocos argumentos, a pesar de haber nacido, según él, en la misma cuna de la elocuencia romana. 
NOTAS

Acaso esta Disertación jocoseria no provoque a nadie a la ira, mucho menos a los mexicanos, "gracias a nuestra superior y natural inteligencia de indios", debida, según ironía de Abad, a nuestro cielo favorable, a nuestros inviernos serenos y risueños, a nuestros veranos lluviosos (Dissertatio, parágrafo 12); pero sin duda, junto a sus enseñanzas, hará pasar un rato agradable, y esto, sin duda, se da gracias al editor, sin importar el modo como lo haya hecho, pero también sin que deje de ponernos a pensar.
Esto es, que sin la Retórica a Herenio editada en la forma en que deploran los modernos editores, ni ellos mismos tuvieran la oportunidad de lucir sus galas de sabiduría; ni la entera Edad Media ni nosotros, la de llenar importantísimos espacios en la enseñanza del arte de la palabra o en otros campos de la cultura.

Esto dicho valga para los demás casos, pero teniendo en cuenta que nada de lo cual significa que debamos llevar la bandera del "àhi se va" cuando es posible la del "más mejor", para no dar lugar a malos pensamientos. 